\title{
Evaluation of Wound Healing Capacity of Selected leaf Extracts using In vitro Scratch Assay with L929 Fibroblasts
}

\author{
Gowthama Prabu Udayakumar', Poorani Gurumallesh ${ }^{1}$ and Baskar Ramakrishnan ${ }^{1 *}$ \\ ${ }^{1}$ Department of Biotechnology, Kumaraguru College \\ of Technology, Coimbatore, Tamil Nadu 641049 India
}

\section{ABSTRACT}

Wound healing is the process by which the skin repairs and maintains itself. Any delay in the healing might result in various skin pathologies like prolonged non-healing and chronic ulceration. Traditional medicines use plant-based products that play an important role in cutaneous wounds. L929 Fibroblast cell line forms the connective tissues, which hold importance by synthesizing extracellular matrix and collagen in the process of wound healing. In the present study, cold percolated ethanol leaf extracts of Beta vulgaris and Psidium guajava were compared for its in vitro wound healing activity through scratch wound assay performed on L929 cells. The rate of healing was examined at regular intervals and determined using ImageJ software. The skin cell re-epithelialization property was identified to be comparatively higher levels in the ethanol extract of Beta vulgaris when compared to that of Psidium guajava. This study aims to compare the in vitro wound healing activity of the selected ethanol extracts with that of the standard positive control, thereby extending its application for in vivo wound healing capacity useful in the cosmetic industries.

KEY WORDS: BETA VULGARIS; COLD PERCOLATION; FIBROBLAST; IMAGEJ; PSIDIUM GUAJAVA; WOUND SCRATCH ASSAY.

\section{INTRODUCTION}

Wound healing is a natural process of replacing the damaged cell or tissue with fresh ones. There are a chain of events occurring within a human body immediately post trauma and with the help of certain pathways, all the biomolecules would contribute to make the healing process a successful one (Sorg, Tilkorn, Hager, Hauser, Et Mirastschijski, 2017). In adult human beings, the dynamic wound healing process is categorized into

\section{ARTICLE INFORMATION}

*Corresponding Author: baskar.r.bt@kct.ac.in

Received 08th Oct 2020 Accepted after revision 14th Dec 2020

Print ISSN: 0974-6455 Online ISSN: 2321-4007 CODEN: BBRCBA

Thomson Reuters ISI Web of Science Clarivate Analytics USA and Crossref Indexed Journal

\section{Clarivate
Analytics}

NAAS Journal Score 2020 (4.31) SJIF: 2020 (7.728)

A Society of Science and Nature Publication,

Bhopal India 2020. All rights reserved.

Online Contents Available at: http//www.bbrc.in/

Doi: http://dx.doi.org/10.21786/bbrc/13.11/15 four different segments namely hemostasis phase, inflammatory phase, the proliferation phase and the remodeling phase. Generally, wound healing happens on its own and does not require any medical examinations. With respect to chronic health conditions like vascular disease and diabetes, the natural wound healing process is slightly impaired (Gosain \& DiPietro, 2004). A majority of mechanisms through which healing occurs has been portrayed, still a lot of pathophysiological process are yet to be decoded.

Researchers identified certain factors to be extremely influential in hindering the natural process of wound healing and they were organized as local and systemic. Local factors have a straight impact on wound, however the systemic factors are related to overall health conditions. Single or multiple factors could be related to the healing process and its very complex to identify the trigger point that's impairing wound healing process (Guo \&t DiPietro, 2010). To overcome the hindrance

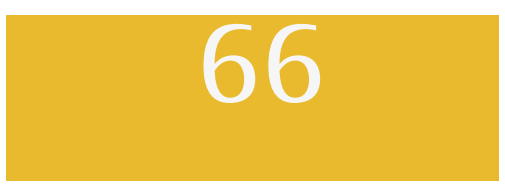


occurring in natural wound healing process, the aids play a very significant role. Extracted biomolecules or the synthetic drugs accelerated the wound healing process by effectively acting on the site on infection.

To regulate wound healing and to fasten it there are a lot of drug formulations being used by a lot of medical practitioners. The rise in human population, shortage in supply of drug molecules and multiple drug resistance are the major triggers pushing the researchers to find an effective alternative to sort out the problem. In multiple dimensions, there are approaches being done to accelerate the chronic wound healing. For an instance, a research group from China are exclusively working on RNA regulations that would facilitate the healing of diabetic chronic wounds (Z.-H. Liang, Pan, Lin, Qiu, \& Zhang, 2020).

The synthetic medicines are offering a wide range of solution; still phytochemicals have its importance on its own. Curcumin contains a lot of bioactive molecules which are very significant in healing the wound. Also, herbal medicine is gaining attention worldwide from the perspective of both producer and user. To a range of patients, herbal medicines has been a supportive therapy / alternative therapy to treat a broad spectrum of ailments. With the emerging advancements purification technology and analytical chemistry, identifying and isolating the bioactive component has become more precise and reliable. Many phytochemicals were extracted multiple aspects and been formulated into various forms like a tablet / capsule / syrup and topical applications.

Understanding the biology of wound healing is absolutely complex as it involves a cascade of events and also many numbers of biomolecules are actively influential in the process (Thangapazham, Sharad, \& Maheshwari, 2016). With progress in research towards phytochemicals in wound healing it was also found that it helps in skin regeneration along with treating the wound. Another important attribute to be taken into consideration is cost effectiveness. As natural resources are present in abundance, the production cost would be invariably lower and hence it could be reachable to all ranges of buyers with respect to commercialization. After a thorough literature review and analyzing previous researches made, this study mainly aims to compare and investigate the in vitro wound healing activity of the selected ethanol extracts of the leaves of Beta vulgaris and Psidium guajava on L929 Fibroblast cells using scratch wound assay. Based on the performance criteria and effectiveness, the scale up of the production could be maximized to meet up the demand.

\section{MATERIAL AND METHODS}

Sample collection and Identification: The whole plant Beta vulgaris was collected from a farm in Ooty, Nilgiris and Psidium guajava with the floral parts was collected from a farm in Devarayapuram, Coimbatore. The plants were authenticated by Scientist In-Charge, Botanical Survey of India, Tamil Nadu Agricultural University
(TNAU), Coimbatore. The voucher specimens of the leaf samples (Psidium guajava - BSI/SRC/5/23/2020/Tech/555 and Beta vulgaris - BSI/SRC/5/23/2020/Tech/556) were stored in the herbarium of the department.

Cold percolation extraction: The leaf samples were dried under shade and ground to coarse powder. Cold extraction was performed using $100 \mathrm{ml}$ of ethanol for 10 grams of the powdered leaf sample by providing a gentle shake continuously for around 24hours. This process was repeated for five batches and the extracts were collected, filtered using Whatman Grade 1 (11m) and stored in brown bottles for further experiments (Chiari-Andréo et al., 2017; Tripathy \& Pradhan, 2013).

In vitro Scratch wound assay: The cell monolayer containing non- transfected L929 fibroblast cells was scraped using a $200 \mu$ l pipette tip, washed to remove the debris and replaced with a suitable medium with the addition of the samples. They were then incubated at $37^{\circ} \mathrm{C}$ for around 18 hours and periodically checked for the cell-cell migration. The period of incubation allows the cell migration condition to complete the created scratch. Using, inverted phase contrast microscope, the scratch was captured before incubation and at regular time intervals, say, 4th, 18th and 24th hour when the positive control exhibited complete closure. Using, ImageJ software, the distance between 2 sides of the scratch i.e., the mean wound area $(\mu \mathrm{m})$ during the healing process was measured (Liang, Park, \&t Guan, 2007; Santhini,et al , 2018).

\section{RESULTS AND DISCUSSION}

Sample collection and Extraction: The preparatory pretreatment methods for the collected leaves were carried out and extracted successfully using cold percolation method, which are essential for the extraction process. Based on the previous work in our lab (Udayakumar et al, 2020), the cold percolated ethanol leaf extracts of both Beta vulgaris and Psidium guajava were found to hold the phytochemical compounds, when compared with the other hot and cold solvent extracts of the leaf.

In vitro scratch wound healing activity: The in vitro scratch wound assay was performed on L929 Fibroblast cell lines (purchased from NCCS, Pune) cultured on minimum essential medium supplemented with Fetal Bovine Serum (FBS). The selected ethanol leaf extracts of beetroot and guava were added to the culture well plates in differing concentrations like $25 \mu \mathrm{g}, 50 \mu \mathrm{g}, 75 \mu \mathrm{g}$ and $100 \mu \mathrm{g}$ along with the standard positive control. The positive control was found to exhibit complete healing, where the wound area of $3835 \mu \mathrm{m}$ was completely closed at the 24th hour (Pooja et al, 2019) (Fig. 1a and Fig. $1 b)$.

Beetroot showed increased cell proliferation on the created wound (wound area $-3331 \mu \mathrm{m}$ ) at a minimum concentration of $25 \mu \mathrm{g}$ with the maximum wound closure of 78\% after 24 hours. At increasing concentrations of,

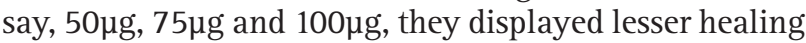


activity due to the increased levels of ethanol suppressing the healing activity of beetroot. Ethanol exposure to the skin cells causes the delay in cell proliferation, collagen synthesis leading to slower epithelial coverage and blood vessel regrowth (Radek et al., 2005; Radek et al,
2009). Guava showed a lesser healing capacity on the created wound (wound area - 3205 $\mu \mathrm{m}$ ) when compared to beetroot with a healing potential of $45 \%$ for $25 \mu \mathrm{g}$ after 24 hours (Table 1).

\begin{tabular}{|c|c|c|c|c|c|c|}
\hline \multirow[t]{2}{*}{ Sample } & \multirow[t]{2}{*}{$\begin{array}{c}\text { Concentration } \\
(\mu \mathrm{g})\end{array}$} & \multirow[t]{2}{*}{$\begin{array}{c}\text { Wound } \\
\text { Area }(\mu \mathrm{m})\end{array}$} & \multicolumn{4}{|c|}{$\begin{array}{l}\text { Time intervals (h) and } \\
\text { percentage of healing (\%) }\end{array}$} \\
\hline & & & 0 & 4 & 18 & 24 \\
\hline \multirow[t]{4}{*}{ Beta vulgaris } & 25 & 3331 & 0 & 13 & 55 & 78 \\
\hline & 50 & 3325 & & 9 & 34 & 57 \\
\hline & 75 & 3505 & & 16 & 20 & 57 \\
\hline & 100 & 3583 & & 17 & 19 & 47 \\
\hline \multirow[t]{4}{*}{ Psidium guajava } & 25 & 3205 & & 36 & 38 & 45 \\
\hline & 50 & 3453 & & 32 & 37 & 42 \\
\hline & 75 & 3559 & & 31 & 41 & 42 \\
\hline & 100 & 3739 & & 30 & 31 & 41 \\
\hline Control & Unknown & 3835 & & 37 & 68 & $>99$ \\
\hline
\end{tabular}

Figure 1a: Microscopic images of in vitro scratch wound healing activity on L929 cells of ethanol extract of extracts of Beta vulgaris and under Cold percolation extraction

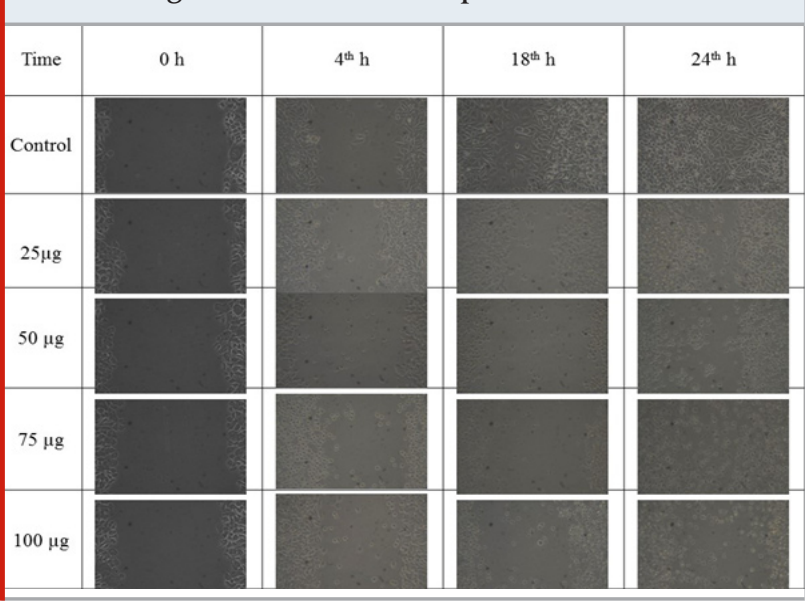

Figure 2a: Graph showing cell proliferation (\%) of the ethanol leaf extracts of Beta vulgaris in differing concentrations captured at 4th, 18th and 24th hour time intervals

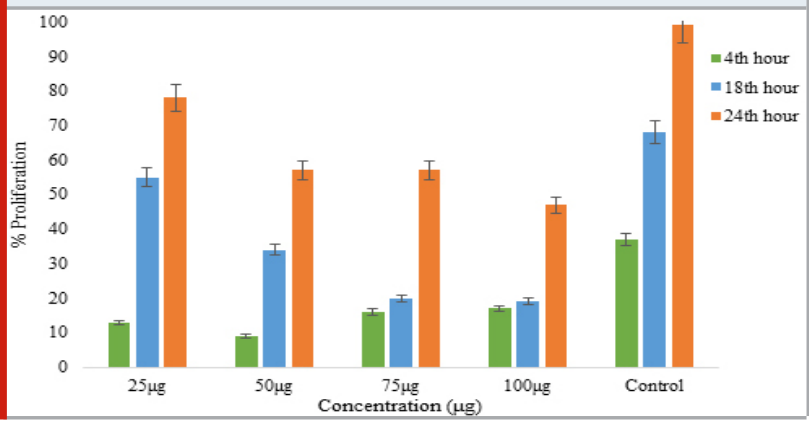

Figure 1b: Microscopic images of in vitro scratch wound healing activity on L929 cells of ethanol extract of extracts of Psidium guajava under Cold percolation extraction

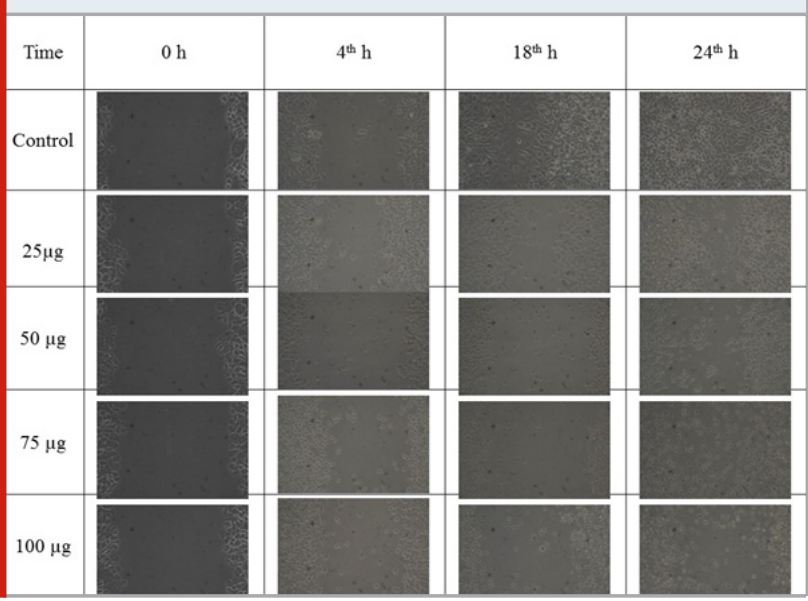

Similar to the beetroot extracts, guava also showed a decreasing linearity over its healing potential due to the inhibition of ethanol against epithelial cell proliferation (Fig. 2). Both the extracts showed an increasing continuance at their intervals, both, 4th and 18th hour with respect to their final healing activity at 24th hour. On the whole, both the selected plant extracts were found to exert comparable wound healing effects with the positive control (Porta et al., 2010).

\section{CONCLUSION}

The scientist fraternity is focusing on decoding the complex wound healing process to simplify the understanding of the process. Ethnopharmacological, conventional and synthetic methods of preparation of 
formulations to treat wounds are existing. In addition to that phytochemical bio active compounds plays a significant role. The present study reported the wound healing activity of phytoconstituents extracts from Beta vulgaris and Psidium guajava and both the extracts exhibited comparable effects on treating wound. The research article would bring in new insights to concentrate on bio-prospect the plant sources to identify more potential bioactive molecules to encounter the global demand.

\section{ACKNOWLEDGEMENTS}

The authors are grateful to the Biotechnology Lab, SITRA, Coimbatore for assisting in the in vitro scratch wound healing analysis.

Conflicts of Interest: All the authors declare no conflict of interest.

\section{REFERENCES}

Chiari-Andréo, B. G., Trovatti, E., Marto, J., De AlmeidaCincotto, M. G. J., Melero, A., Corrêa, M. A., ... Isaac, V. L. B. (2017). Guava: Phytochemical composition of a potential source of antioxidants for cosmetic and/ or dermatological applications. Brazilian Journal of Pharmaceutical Sciences, 53(2). https://doi.org/10.1590/ s2175-97902017000216141

Gosain, A., \&t DiPietro, L. A. (2004). Aging and wound healing. World Journal of Surgery, 28(3), 321-326.

Guo, S. al, \&t DiPietro, L. A. (2010). Factors affecting wound healing. Journal of Dental Research, 89(3), 219-229.

Liang, C. C., Park, A. Y., \& Guan, J. L. (2007). In vitro scratch assay: A convenient and inexpensive method for analysis of cell migration in vitro. Nature Protocols, 2(2), 329-333. https://doi.org/10.1038/nprot.2007.30

Liang, Z.-H., Pan, Y.-C., Lin, S.-S., Qiu, Z.-Y., \& Zhang, Z. (2020). LncRNA MALAT1 promotes wound healing via regulating miR-141-3p/ZNF217 axis. Regenerative Therapy, 15, 202-209.

Pooja, R., Vadodaria, K., \& Vidhya, S. (2019). Synthesis of bacterial cellulose and herbal extract for the development of wound dressing. Materials Today: Proceedings, 15, 284-293. https://doi.org/10.1016/j. matpr.2019.05.007
Porta, K., Fernandes, S., Bussadori, S. K., Marques, M. M., Sumie, N., Wadt, Y., ... Martins, M. D. (2010). Healing and cytotoxic effects of Psidium guajava ( Myrtaceae ) leaf extracts, 9(4), 9-14. https://doi.org/https://doi. org/10.20396/bjos.v9i4.8641730

Radek, K. A., Matthies, A. M., Burns, A. L., Heinrich, S. A., Kovacs, E. J., \&t DiPietro, L. A. (2005). Acute ethanol exposure impairs angiogenesis and the proliferative phase of wound healing. American Journal of Physiology - Heart and Circulatory Physiology, 289(3 58-3), 1084-1090. https://doi.org/10.1152/ ajpheart.00080.2005

Radek, K. A., Ranzer, M. J., \&t DiPietro, L. A. (2009). Brewing complications: the effect of acute ethanol exposure on wound healing. Journal of Leukocyte Biology, 86(5), 1125-1134. https://doi.org/10.1189/ jlb.0209103

Santhini, E., Pramila, V. M., Shalini, M., Vignesh Balaji, R., \&t Chellamani, K. P. (2018). Preparation and characterization of PLGA-based biocompatible nanoparticles for sustained delivery of growth factor for wound healing applications. Current Science, 115(7), 1287-1296. https://doi.org/10.18520/cs/v115/i7/12871296

Sorg, H., Tilkorn, D. J., Hager, S., Hauser, J., \& Mirastschijski, U. (2017). Skin wound healing: an update on the current knowledge and concepts. European Surgical Research, 58(1-2), 81-94.

Thangapazham, R. L., Sharad, S., \&t Maheshwari, R. K. (2016). Phytochemicals in Wound Healing. Advances in Wound Care, 5(5), 230-241. https://doi.org/10.1089/ wound.2013.0505

Tripathy, G., \& Pradhan, D. (2013). Evaluation of in-vitro anti-proliferative activity and in-vivo immunomodulatory activity of Beta vulgaris. Asian Journal of Pharmaceutical and Clinical Research, 6(SUPPL.1), 127-130.

Udayakumar, G. P., Inbaraj, A., Baskar, K. K., Muthuraman, S., \&t Ramakrishnan, B. (2020). Study on the in vitro antioxidant properties of selected traditional medicinal plants. Journal of Pharmacognosy and Phytochemistry, 9(4), 1831-1837. https://doi. org/10.22271/phyto.2020.v9.i4y.12023 